\title{
Nutritional Status of the Adolescent Boys of a Recognized Charitable Orphanage in Dhaka City, Bangladesh
}

\author{
Ropak Chandra Roy ${ }^{1}$, Md. Sahabuddin², Sumon Chandra Debnath ${ }^{3}$, Md. Jakir Hosaain ${ }^{4}$, Md. Azmol \\ Hossain $^{5}$, Sentu Chandra Barman ${ }^{6}$, Anamul Hasan ${ }^{7}$, Mahbub Jubayer ${ }^{8}$, Jamal Uddin ${ }^{8}$, Md. Habibur \\ Rahman $^{8}$, Md. Sherajul Haque ${ }^{1}$, and Banosree Saha ${ }^{8}$
}

\begin{abstract}
${ }^{1}$ Dept. of Physiotherapy, Gono Bishwabidalay, Dhaka, Bangladesh; ${ }^{2}$ Dept. of Biotechnology and Genetic Engineering, BSMRSTU, Gopalganj, Bangladesh; ${ }^{3}$ Civil Surgeon Office, Chattogram, Bangladesh; ${ }^{4}$ Dept. of Biochemistry and Microbiology, North South University, Dhaka, Bangladesh; ${ }^{5}$ Eastern care hospital Ltd, Dhaka, Bangladesh; ${ }^{6}$ New Medi Fair diagnosis centre, Dhaka, Bangladesh; ${ }^{7}$ MAYFAIR Wellness Clinic ltd, Dhaka, Bangladesh; ${ }^{2}$ Dept. of Microbiology, Jahangirnagar University, Dhaka, Bangladesh; ${ }^{8}$ Gonoshasthya Samaj Vittik Medical \& College Hospital, Dhaka, Bangladesh.

*Correspondence: ropak.mph111@gmail.com
\end{abstract}

\begin{abstract}
This cross-sectional research was managed for the deduction of nutritional condition among adolescent boys of a perceived charitable orphanage in Dhaka city, Bangladesh. The sample size of the study was 100. This research set up the mean age of the study sample as $9.93 \pm 2.392$ years and modes Body Mass Index (BMI) were $14.48 \pm$ 2.385. Among them of $60 \%$ of the participants were illiterate and $40 \%$ had a primary level of education. Of the participants, $100 \%$ were lay hold of vegetables, and rice. Among them $92 \%, 89 \%, 64 \%, 47 \%$, and $4 \%$ of the participants were taken chicken, fast food, beef, bread, and mutton respectively. Among them, $96 \%$ were lay hold of sufficient food and $4 \%$ lay hold of insufficient food daily. The present study shows that $96 \%$ were taken education from Madrasha, $4 \%$ were taken general education. The current research also focused that $92 \%$ of the participants had information about own hygiene and $8 \%$ had not, and among them, $84 \%, 80 \%, 76 \%$ and $70 \%$ of the participants were regulated personal hygiene by nail and hair trimming, hand washes practicing by soap after toileting, utilize toothbrush and paste daily and hand wash performing by soap after taking food respectively. Of them, $57 \%, 53 \%, 49 \%, 16 \%$ and $2 \%$ of the participants had information about own hygiene by doctors, friends, television, radio, and poster respectively. There was a statistically noteworthy association between age with the volume of food, information about own hygiene and BMI was (0.016, 0.022 and 0.000).
\end{abstract}

Keywords: Adolescent Boys, Nutritional Status, Charitable Orphanage, Deficiency, and Hygiene

\section{INTRODUCTION}

Deficiency of calories and certain micronutrients are known to cause growth retardation in children and adolescents. During adolescence, lifelong dietary and related habits are established, presenting a unique opportunity to instill positive health behaviors (Sawyer et al., 2012). The extent of variations in intake of nutrients occurring in a homogen eous population provides useful information (Shafiee et al., 2015). Nutritional status is the condition of the body in those respects influenced by the diet; the levels of nutrients in the body and the ability of those levels to maintain normal metabolic integrity (Beaudry et al., 2004). Food choices in low-resource settings are 
constrained by high levels of poverty, leading to food insecurity, poor diet diversity, and lack of access to nutritious food (Akseer et al., 2017). Boys also have increased nutritional requirements for adequate physical growth and development such as muscle mass accumulation, and they experience a high burden of malnutrition (Bundy et al., 2018). Adolescence is a period of rapid growth and maturation in human development (Maiti et al., 2011). There has been a worldwide significant change in the nutritional status of adolescents during the past 2 decades because of global economic development and urbanization (Wang et al., 2009). Adolescents' malnutrition, an alarming public health problem worldwide (Chen et al., 2013) is imposing a great threat to the future generation via a vicious cycle. In Malaysia, a moderately high prevalence of anemia has been reported amongst infants, young children and women of childbearing age (Foo et al., 2004). It is a vulnerable time, particularly for girls who have increased nutritional requirements due to menstruation and often have restricted access to nutritious food, education, and economic opportunities due to gendered cultural norms (Ivers et al., 2011; Shahen et al., 2019). In this trial, frequent standardized hand rubbing with ethanol-based disinfectant did not reduce the weekly prevalence of either type of infections (Hovi et al., 2017).

Rates of malnutrition in Bangladesh are among the highest in the world, with six million children estimated to be chronically undernourished. The

\section{MATERIALS AND METHODS}

Study Design and Population - It was a descriptive type of cross-sectional study. The sample population has consisted of adolescence boys living in a Mirpur- 6 charitable orphanage.

Study Area and Site - The study was conducted in the Mirpur area of Dhaka city. The site was in Mirpur charitable organization -

Location Mirpur-6, Dhaka, Bangladesh

Number of adolescent boys - 600 proportion of thinness was significantly higher among subjects who suffered fromiron deficiency anaemia (Kurniawan et al., 2006). Surprisingly, $73.8 \%$ of the participants were not aware of the sources of iron-rich foods (Kabir et al., 2010).

Factors associated with the increased use of iron supplements were related to awareness of the boys abou textra nutrients and their access to mass media and education (Alam et al., 2010). Many Iranian adolescent boys are Fe-deficient, but it is unclear whether $\mathrm{Fe}$ deficiency is associated with other nutritional risk indicators. Anemia was more prevalent among overweight Fe-deficient adolescents than among those Fe- deficient and at risk for overweight or normal weight $(34.1 \%$ v. $28.8 \%$ v. $27.8 \%$, respectively; $\mathrm{P}<0.001$ ) (Eftekhari et al., 2014). There is a need to improve their hemoglobin status through dietary modification along with preventive supplemen tation and nutrition education (Choudhary et al., 2006).

The main objectives of the studies to assess the nutritional status among the adolescent boys of a selected recognized a charitable organization in Dhaka city, and to find out the socio-demographic factors, nutritional status, charitable organization related variables of the respondents, and to evaluate the association between education and BMI of the respondents.

Facilities- Boarding, Education, Food, Dress, Medical facilities

Study Period and Sample Size - The study will be conducted from 1st June 2018 to 30th September 2018. Following formula was used to determine the sample size.

$$
n=\frac{z^{2} p q}{d^{2}}
$$

Here

$$
\begin{aligned}
& \mathrm{n}=\text { the desired sample size } \\
& \mathrm{z}=\text { the standard normal deviate usually }
\end{aligned}
$$


set at 1.96 which correspondents to $95 \%$ confidence level

$\mathrm{p}=49 \%{ }^{14}$ (Estimated prevalence)

$\mathrm{q}=1-\mathrm{p}=1-0.49$

$\mathrm{q}=0.51$

$\mathrm{d}=$ degree of accuracy desired, usually set at $0.05 \%$.

Now, the required a sample size

$$
\begin{gathered}
n=\frac{z^{2} p q}{d^{2}} \\
n=\frac{(1.96)^{2} \times 0.49 \times 0.51}{(0.05)^{2}} \\
=384.006
\end{gathered}
$$

So, required the sample size is 384 .

The researcher took 100 samples by kind permission of Guide due to financial and time limitation.

\section{Inclusion and Exclusion criteria:}

Inclusion Criteria - Those who were willing to give consent and participate in the study. Stayed in the orphanage for more than 2 years.

\section{RESULT AND DISCUSSION}

The cross-sectional type of descriptive study was conducted for nutritional status among the adolescent boys of a selected recognized charitable organization in Dhaka city with a sample size of 100 . A pre-tested modified interviewer administrated semi-structured questionnaires was used to collect the information. Section A contains socio-demographic related

Table 1: Distribution of the respondents by age $(n=100)$

\begin{tabular}{|c|c|c|}
\hline Age (years) & Frequency & $\begin{array}{c}\text { Percentage } \\
(\mathbf{\%})\end{array}$ \\
\hline$<10$ years & 60 & 60 \\
\hline $11-13$ years & 36 & 36 \\
\hline 14 years and above & 4 & 4 \\
\hline Total & $\mathbf{1 0 0}$ & $\mathbf{1 0 0}$ \\
\hline Mean \pm SD & \multicolumn{2}{|c|}{$\mathbf{9 . 9 3} \pm \mathbf{2 . 3 9 2}$} \\
\hline
\end{tabular}

Exclusion Criteria - Mentally or physically handicapped.

Sampling technique and Data collection tools Non-randomized purposive sampling technique was applied to collect the data. A semi-structured pretested, modified questionnaire will be used to collect the data.

Data management and analysis - After the collection of data of the respondents were organized. Data was entered into the computer into a data base in the software package. Statistical package for social science (SPSS) Version 16.0 (Polar engineering and consulting, Chicago) using descriptive statistics such as frequency, distribution, range, mean, and percentage.

Scores and percentages were computed and presented $\mathrm{i}$ $\mathrm{n}$ tabular form, charts, and graphs as appropriate. Further, it was analyzed with the help of the chisquare test and P-value. Finally, the data was interpreted on the basis of the study findings.

variables, Section B contains nutritional related variables, Section C contains charitable organization related variables and Section D contains IEC related variables. All the data were entered and analyzed by using Statistical packages for social science (SPSS) software version 16.0 (Chicago).

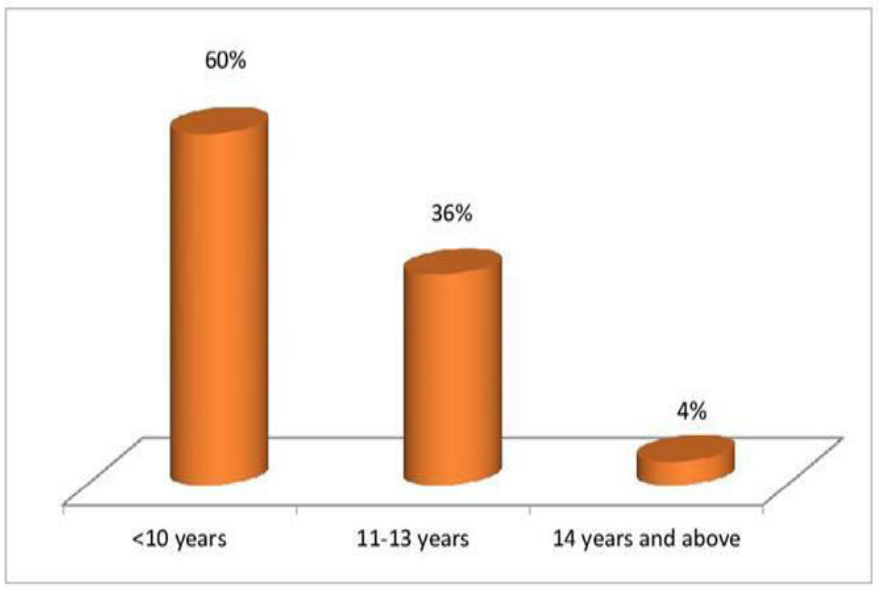

Fig 1: Distribution of the respondents by age. 
As shown in Table 1, 60\%, 36\% and 4\% of the respondents belong to <10 years of age, 11-13 years and 14 years respectively with the mean age $9.93 \pm 2.392$ years (Fig $\mathbf{1}$ ).

Table 2: Distribution of the respondents by education $(n=100)$

\begin{tabular}{|l|c|c|}
\hline Education & Frequency & $\begin{array}{c}\text { Percentage } \\
(\boldsymbol{\%})\end{array}$ \\
\hline Illiterate & 60 & 60 \\
\hline Primary & 40 & 40 \\
\hline Total & $\mathbf{1 0 0}$ & $\mathbf{1 0 0}$ \\
\hline
\end{tabular}

Table 3: Distribution of the respondents by height $(n=100)$

\begin{tabular}{|l|c|c|}
\hline Height & Frequency & $\begin{array}{c}\text { Percentage } \\
(\mathbf{\%})\end{array}$ \\
\hline$<122 \mathrm{~cm}$ & 31 & 31 \\
\hline $123-152 \mathrm{~cm}$ & 59 & 59 \\
\hline$>153 \mathrm{~cm}$ & 10 & 10 \\
\hline Total & $\mathbf{1 0 0}$ & $\mathbf{1 0 0}$ \\
\hline
\end{tabular}

Table 4: Distribution of the respondents by body weight $(n=100)$

\begin{tabular}{|c|c|c|}
\hline $\begin{array}{c}\text { Body } \\
\text { weight }\end{array}$ & Frequency & $\begin{array}{c}\text { Percentage } \\
(\mathbf{\%})\end{array}$ \\
\hline$<20 \mathrm{~kg}$ & 37 & 37 \\
\hline $21-40 \mathrm{~kg}$ & 57 & 57 \\
\hline$>41 \mathrm{~kg}$ & 6 & 6 \\
\hline Total & $\mathbf{1 0 0}$ & $\mathbf{1 0 0}$ \\
\hline Mean $\mathbf{+}$ SD & & \\
\hline
\end{tabular}

Table 2 shows that $60 \%$ of the respondents were illiterate and $40 \%$ were primary. Table 3 found that $59 \%, 31 \%$ and $10 \%$ of the respondents were $123-152$ $\mathrm{cm},<122 \mathrm{~cm}$ and were $>153 \mathrm{~cm}$ respectively. Table 4 shows that $57 \%$ of the respondents were $21-40 \mathrm{~kg}$, $37 \%$ were $<20 \mathrm{~kg}$ and $6 \%$ were $>41 \mathrm{~kg}$ respectively with mean body weight were $24.92 \pm 8.199 \mathrm{~kg}$. Table 5 reveals that $59 \%$ of the respondents were underweight
Table 5: Distribution of the respondents by BMI $(\mathrm{n}=100)$

\begin{tabular}{|l|l|c|}
\hline \multicolumn{1}{|c|}{ BMI } & Frequency & Percentage (\%) \\
\hline Underweight $(<14)$ & 59 & 59 \\
\hline Normal (14-20) & 41 & 41 \\
\hline Total & $\mathbf{1 0 0}$ & $\mathbf{1 0 0}$ \\
\hline Mean \pm SD & \multicolumn{2}{|c|}{$\mathbf{1 4 . 4 8} \pm \mathbf{2 . 3 8 5}$} \\
\hline
\end{tabular}

Table 6: Distribution of the respondents by type of charitable organization $(n=100)$

\begin{tabular}{|l|c|c|}
\hline $\begin{array}{l}\text { Type of the } \\
\text { Charitable } \\
\text { organization }\end{array}$ & Frequency & $\begin{array}{c}\text { Percentage } \\
(\%)\end{array}$ \\
\hline Orphanage & 100 & 100 \\
\hline $\begin{array}{l}\text { Christian } \\
\text { missionary }\end{array}$ & 0 & 0 \\
\hline Hindu ashram & 0 & 0 \\
\hline Total & $\mathbf{1 0 0}$ & $\mathbf{1 0 0}$ \\
\hline
\end{tabular}

Table 7: Distribution of the respondents by funding organizations of the orphanage $(n=100)$

\begin{tabular}{|l|c|c|}
\hline $\begin{array}{l}\text { Funding } \\
\text { organizations of } \\
\text { the orphanage }\end{array}$ & Frequency & $\begin{array}{c}\text { Percentage } \\
(\mathbf{\%})\end{array}$ \\
\hline Government & 0 & 0 \\
\hline NGO & 0 & 0 \\
\hline Trusty board & 0 & 0 \\
\hline Privet company & 100 & 100 \\
\hline Total & $\mathbf{1 0 0}$ & $\mathbf{1 0 0}$ \\
\hline
\end{tabular}

and $41 \%$ were normal with the mean BMI were $14.48 \pm 2.385 \mathrm{~kg}$. These findings are similar to the finding of a study carried out by Alam N. et al., 2010.

Table 6 revealed that $100 \%$ of the respondents were living in the orphanage. Table 7 shows that $100 \%$ of the respondents had funding organizations of the orphanage were Private Company. 
Table 8: Distribution of the respondents by types of food (Multiple responses)

\begin{tabular}{|l|c|c|}
\hline Types of food & Frequency & Percentage (\%) \\
\hline Vegetable & 100 & 100 \\
\hline Chicken & 92 & 92 \\
\hline Mutton & 4 & 4 \\
\hline Beef & 64 & 64 \\
\hline Rice & 100 & 100 \\
\hline Bread & 47 & 47 \\
\hline Fast food & 89 & 89 \\
\hline
\end{tabular}

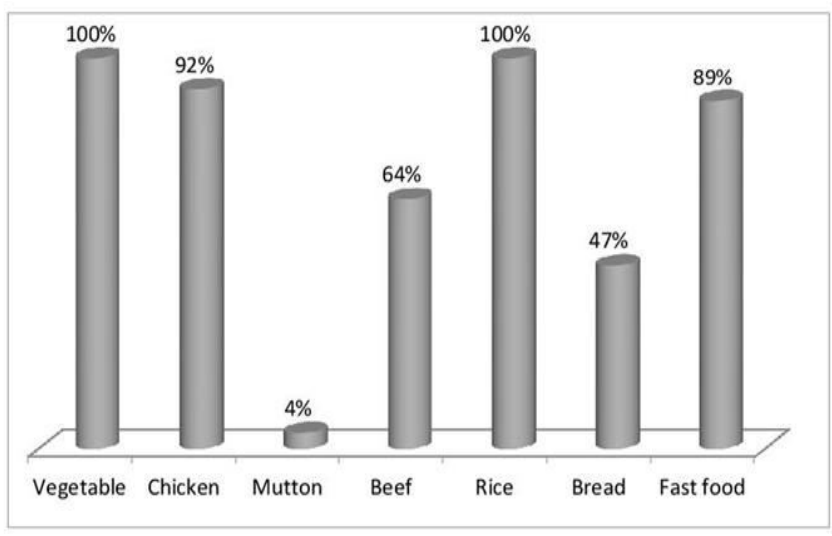

Fig 2: Distribution of the respondents by types of food (Multiple responses).

Table 8 found that $100 \%$ of the respondents were taken vegetables and rice. Among them, 92\%, 89\%, 64\%, 47\% and $4 \%$ of the respondents were taken chicken, fast food, beef, bread, and mutton respectively (Fig 2 ).

Table 9: Distribution of the respondents by amount of food $(n=100)$

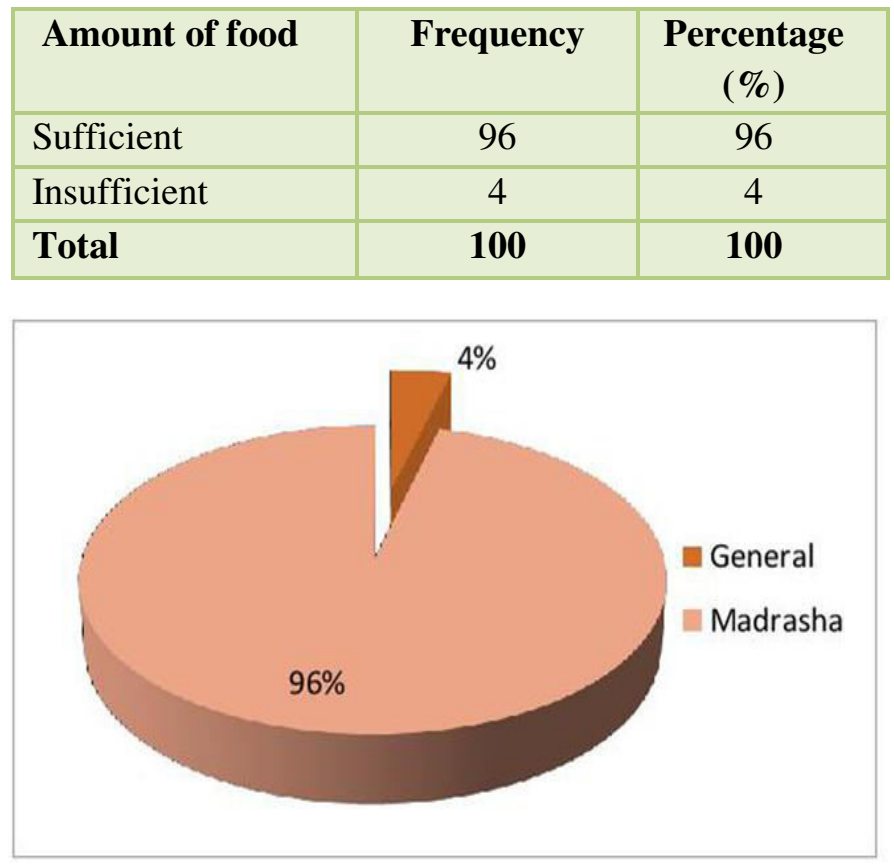

Fig 4: Distribution of the respondents by type of education.

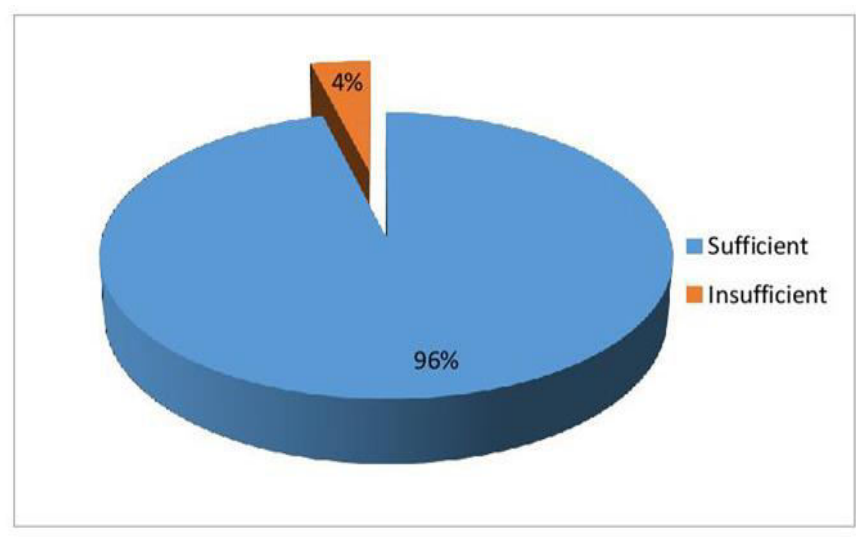

Fig 3: Distribution of the respondents by the amount of food.

Table 10: Distribution of the respondents by type of education $(\mathrm{n}=100)$

\begin{tabular}{|l|l|l|}
\hline Type of education & Frequency & Percentage (\%) \\
\hline General & 4 & 4 \\
\hline Madrasha & 96 & 96 \\
\hline Total & $\mathbf{1 0 0}$ & $\mathbf{1 0 0}$ \\
\hline
\end{tabular}

Table 9 found that $96 \%$ of the respondents were taken sufficient food whereas $4 \%$ had insufficient food intake (Fig 3) and Table 10 found that $96 \%$ of the respondents were took education from Madrasha, and 4\% took general education (Fig 4). 
Table 11: Distribution of the respondents by information about personal hygiene $(\mathrm{n}=100)$

\begin{tabular}{|c|c|c|}
\hline $\begin{array}{l}\text { Information about } \\
\text { personal hygiene }\end{array}$ & Frequency & Percentage (\%) \\
\hline Yes & 92 & 92 \\
\hline No & 8 & 8 \\
\hline Total & $\mathbf{1 0 0}$ & $\mathbf{1 0 0}$ \\
\hline
\end{tabular}
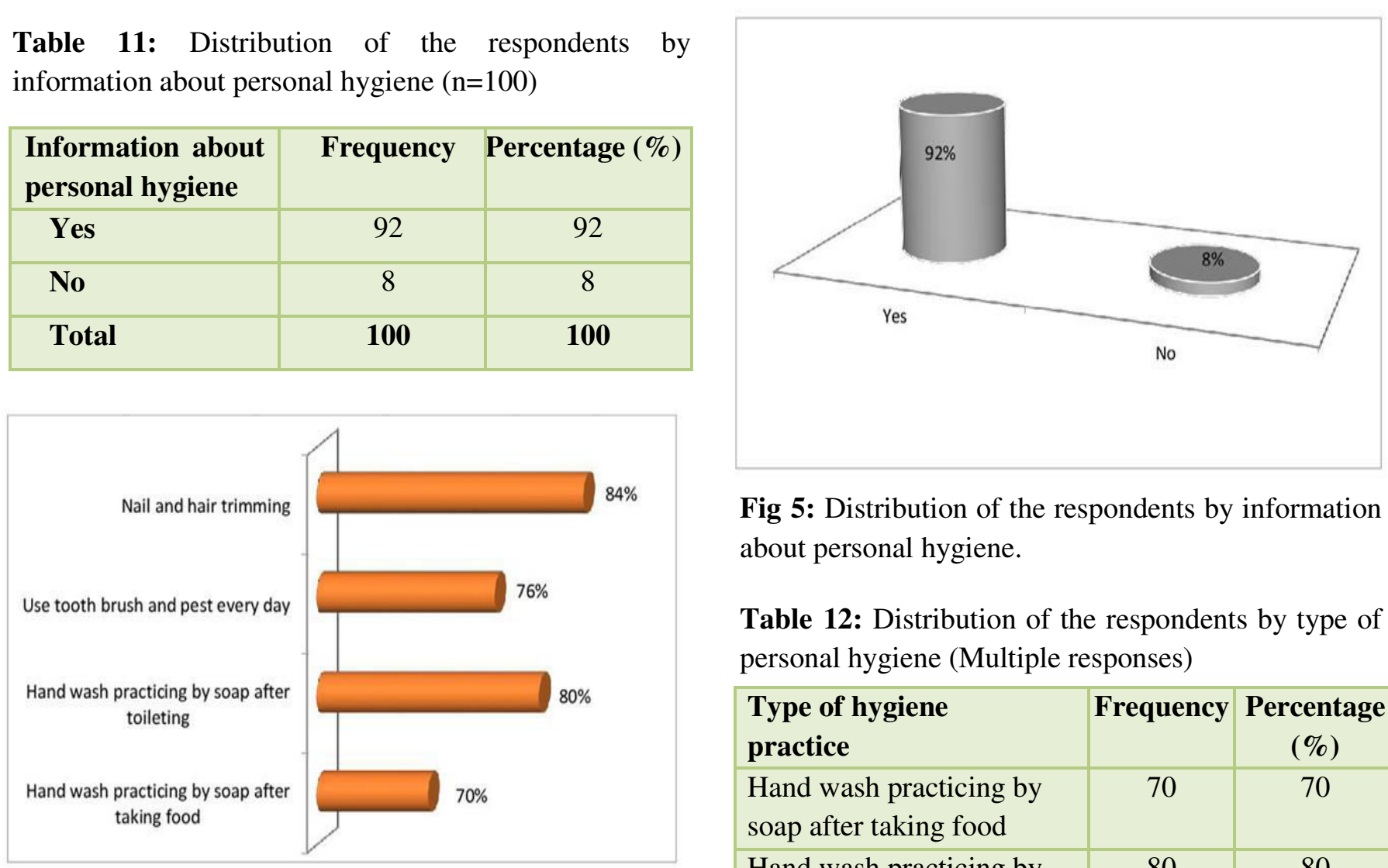

Fig 6: Distribution of the respondents by type of personal hygiene (Multiple responses).

Fig 5: Distribution of the respondents by information about personal hygiene.

Table 12: Distribution of the respondents by type of personal hygiene (Multiple responses)

\begin{tabular}{|l|c|c|}
\hline $\begin{array}{l}\text { Type of hygiene } \\
\text { practice }\end{array}$ & Frequency & $\begin{array}{c}\text { Percentage } \\
(\%)\end{array}$ \\
\hline $\begin{array}{l}\text { Hand wash practicing by } \\
\text { soap after taking food }\end{array}$ & 70 & 70 \\
\hline $\begin{array}{l}\text { Hand wash practicing by } \\
\text { soap after toileting }\end{array}$ & 80 & 80 \\
\hline $\begin{array}{l}\text { Use tooth brush and pest } \\
\text { every day }\end{array}$ & 76 & 76 \\
\hline Nail and hair trimming & 84 & 84 \\
\hline
\end{tabular}

Table 11 shows that $92 \%$ of the respondents had information about personal hygiene and $8 \%$ had not (Fig 5) and Table 12 found that $84 \%, 80 \%, 76 \%$ and $70 \%$ of the respondents were maintain personal hygiene by Nail and hair trimming, Hand wash practicing by soap after toileting, use toothbrush and pest every day and Hand wash practicing by soap after taking food respectively (Fig 6). These findings were similar to the finding of a study carried out by Hovi T. et al., 2017

Table 13: Distribution of the respondents by information about personal hygiene by mass media (Multiple responses)

\begin{tabular}{|l|c|c|}
\hline Mass media & Frequency & $\begin{array}{c}\text { Percentage } \\
(\mathbf{\%})\end{array}$ \\
\hline Radio & 16 & 16 \\
\hline Television & 49 & 49 \\
\hline Poster & 2 & 2 \\
\hline Print media & 0 & 0 \\
\hline $\begin{array}{l}\text { Community } \\
\text { health worker }\end{array}$ & 0 & 0 \\
\hline Doctors & 57 & 57 \\
\hline Friends & 53 & 53 \\
\hline
\end{tabular}

Table 14: Distribution of the respondents by the association between Age and Amount of the food $(\mathrm{n}=100)$

\begin{tabular}{|l|l|l|l|l|}
\hline \multirow{2}{*}{ Age } & \multicolumn{2}{|c|}{ Amount of the food } & Total & p-value \\
\cline { 1 - 4 } & Sufficient & Insufficient & & \\
\hline$<10$ years & 56 & 4 & 60 & \multirow{2}{*}{0.016} \\
\hline 11-13 years & 36 & 0 & 36 & \\
\hline $\begin{array}{l}\text { 14 years and } \\
\text { above }\end{array}$ & 4 & 0 & 4 & \\
\hline Total & $\mathbf{9 6}$ & $\mathbf{4}$ & $\mathbf{1 0 0}$ & \\
\hline
\end{tabular}


Table 13 reveals that $57 \%, 53 \%, 49 \%, 16 \%$ and $2 \%$ of the respondents had information about personal hygiene by doctors, friends, television, radio, and poster respectively. Table 14 finds that P- value was 0.016 which was less than 0.05 that was a statistically significant association between Age and Amount of the food ( $\mathrm{P}$ value obtained from Pearson Chi-square $(\chi 2)$ test). Table 15 finds that $\mathrm{P}$ - value was 0.022 which was

Table 15: Distribution of the respondents by the association between Age and information about personal hygiene $(n=100)$

\begin{tabular}{|c|c|c|c|c|}
\hline \multirow[t]{2}{*}{ Age } & \multicolumn{2}{|c|}{$\begin{array}{c}\text { Information about } \\
\text { personal hygiene }\end{array}$} & \multirow[t]{2}{*}{ Total } & p-value \\
\hline & Yes & No & & \multirow{5}{*}{0.022} \\
\hline$<10$ years & 56 & 4 & 60 & \\
\hline $11-13$ years & 32 & 4 & 36 & \\
\hline $\begin{array}{l}14 \text { years and } \\
\text { above }\end{array}$ & 4 & 0 & 4 & \\
\hline Total & 92 & 8 & 100 & \\
\hline
\end{tabular}

$P$ value obtained from Pearson Chi-square $\left(\chi^{2}\right)$ test

\section{CONCLUSION}

The present study was designed to assess the nutritional status of the adolescent boys of a recognized charitable orphanage in Dhaka city and also their nutrient intake. Institutional environments play an important and necessary role in orphaned care and, at least in this setting, provide a benchmark against which community performance should be measured. The overall nutritional status among study subjects was not good. The major finding of the study was that $100 \%$ of respondents were taken vegetables and rice. Among them, 92\%, 89\%, 64\%, 47\% and 4\% of the respondents were taken chicken, fast food, beef, bread, and mutton respectively. Among them, 96\% were taken enough food whereas $4 \%$ had insufficient less than 0.05 that was the statistically significant association between Age and Information about personal hygiene. Table 16 finds that $\mathrm{P}$ - value was 0.000 which was less than 0.05 that was the statistically significant association between Age and BMI.

Table 16: Distribution of the respondents by the association between Age and information about BMI $(\mathrm{n}=100)$

\begin{tabular}{|l|l|l|l|l|}
\hline \multirow{2}{*}{ Age } & \multicolumn{2}{|c|}{ BMI } & Total & p-value \\
\cline { 2 - 4 } & $<\mathbf{1 4}$ & $>\mathbf{1 5}$ & & \\
\hline$<10$ years & 45 & 15 & 60 & \\
\hline $11-13$ years & 12 & 24 & 36 & 0.000 \\
\hline $\begin{array}{l}14 \text { years } \\
\text { and above }\end{array}$ & 2 & 2 & 4 & \\
\hline $\begin{array}{l}\text { Total } \\
\text { Total }\end{array}$ & 59 & 41 & 100 & \\
\hline
\end{tabular}

food intake. The study further showed that, $92 \%$ of the respondents had information about personal hygiene and $8 \%$ had not, and maintain personal hygiene by nail and hair trimming, hand washes practicing by soap after toileting, use toothbrush and pest everyday and hand wash practicing by soap after taking food respectively. There was a statistically significant association between age with the amount of food, information about personal hygiene and BMI was (0.016, 0.022 and 0.000). The present study concluded that nutritional status among the adolescent boys of a selected recognized charitable organization in Dhaka city was conducted and it was observed through BMI and mean nutrient intake. 


\section{ACKNOWLEDGEMENTS}

This research was cordially supported with proper guidance and help for data analysis in the Dept. of Physiotherapy of the Gono Bishwabidyalay, Savar, Dhaka, Bangladesh. Heartiest thanks to the co-authors of the study to conduct the successful research work.

\section{REFERENCES}

1. Akseer, N., Al-Gashm, S., Mehta, S., Mokdad, A., \& Bhutta, Z. A. (2017). Global and regional trends in the nutritional status of young people: a critical and neglected age group. Ann $N Y$ Acad Sci. 1393(1), 3-20.

2. Alam N, Roy SK, Ahmed T, Ahmed AM. (2010). Nutritional status, dietary intake, and relevant knowledge of adolescent boys in rural Bangladesh. J Health Popul Nutr. 28(1): 86-94

3. Beaudry M, Hamelin A-M, Delisle H. (2004). Public nutrition: an emerging paradigm. Canadian J. of Public Health. 95(5): 375-7

4. Bundy, D. A. P., de Silva, N., Horton, S., Patton, G. C., Schultz, L., \& Jamison, D. T. (2018). Investment in child and adolescent health and development: key messages from Disease Control Priorities, 3rd Edition. Lancet, 391(10121), 687-699.

5. Chen W., and Shi Z. (2013). The Trend in gender disparities of BMI and height between 2004 and 2011 among adolescents aged 17-18 years in Changzhou China. Asia Pacific J. of clinical nutrition. 22(3): 466-73

6. Choudhary A, Moses PD, Mony P, Mathai M. (2006). Prevalence of anaemia among adolescent boys in the urban slums of Vellore, South India. Trop Doct. 36(3): 167-169

7. Eftekhari M, Mozaffari-Khosravi H, Shidfar F. (2009). The relationship between BMI and iron status in iron-deficient adolescent Iranian boys. Public Health Nutr. 12(12): 2377-2381

8. Foo LH, Khor GL, Tee ES, Prabakaran D. (2004). Iron status and dietary iron intake of adolescents from a rural community in Sabah, Malaysia. Asia Pac J Clin Nutr. 13(1): 48-55

9. Hovi T, Ollgren J, Savolainen-Kopra C. (2017).

\section{CONFLICTS OF INTEREST}

The authors declare that they have no competing interests with respect to the research.

Intensified hand-hygiene campaign including soap-and-water wash may prevent acute infections in office workers, as shown by a recognized-exposure -adjusted analysis of a randomized trial. BMC Infect Dis. 17(1): 47

10. Ivers, L. C., \& Cullen, K. A. (2011). Food insecurity: special considerations for women. Am J Clin Nutr. 94(6), 1740-1744.

11. Kabir Y, Shahjalal HM, Saleh F, Obaid W. (2010). Dietary pattern, nutritional status, anaemia and anaemia-related knowledge in urban adolescent college boys of Bangladesh. $J$ Pak Med Assoc. 60(8): 633-638

12. Kurniawan YA, Muslimatun S, Achadi EL, Sastroamidjojo S. (2006). Anaemia and iron deficiency anaemia among young adolescent boys from the peri-urban coastal area of Indonesia. Asia Pac J Clin Nutr. 15(3): 350-356

13. Maiti, S., Ali, K. M., De, D., Bera, T. K., Ghosh, D., Paul, S., Jana, K. (2011). A Comparative Study on Nutritional Status of Urban and Rural Early Adolescent School Girls of West Bengal, India. J. of Nepal Paediatric Society. 31(3), 169-174

14. Sawyer, S. M., R. A., Bearinger, L. H., Blakemore, S. J., Dick, B., Ezeh, A. C., \& Patton, G. C. (2012). Adolescence: a foundation for future health. Lancet. 379(9826), 1630-1640

15. Shafiee S, Mesgarani M, Begum K. (2015). Assessment of nutritional status among adolescent boys in an urban population of South India. Glob J Health Sci. 7(3): 40865

16. Shahen MZ, Mahmud S, Rony MH, Sohana SN, Imran MAS, Al Maruf MA, Azim MAA, Islam MM, Islam MR, Uddin ME and Alam MS. (2019). Effect of Antibiotic Susceptibility and 
Inhibitory Activity for the Control of Growth and Survival of Microorganisms of Extracts of Calendula officinalis. Eur. J. Med. Health Sci. 1(1), 1-9 https://doi.org/10.34104/ejmhs.019

17. Wang, Y., Chen, H. J., Shaikh, S., \& Mathur, P.
(2009). Is obesity becoming a public health problem in India? Examine the shift from underto overnutrition problems over time. Obesity Reviews.

http://dx.doi.org/10.1111/j.1467-789X.2009.00 568.x

Citation: Roy RC, Sahabuddin M, Debnath SC, Hosaain MJ, Hossain MA, Barman SC, Hasan A, Jubayer M, Uddin J, Rahman MH, Haque MS, and Saha B. (2019). Nutritional status of the adolescent boys of a recognized charitable orphanage in Dhaka city, Bangladesh. Eur. J. Med. Health Sci., 1(3), 10-18. https://doi.org/10.34104/ejmhs.01018 C) 